\title{
THE STATE CORPORATE CLOUD COMPUTING- BASED NETWORK FOR REGISTRATION OF POTENTIALLY DANGEROUS OBJECTS
}

\author{
Andrey MELENETS
}

\begin{abstract}
This papers presents the considerations for maintaining information resources of the state with implementation of cloud computing. In particular, it examines a scheme for maintaining the state register of potentially dangerous objects on the basis of cloud computing technology. Special attention is paid to the issue of information protection in cloud computing and the implementation of the hybrid cloud model for maintaining information resources of the state.
\end{abstract}

Keywords: State information resource, cloud computing, hybrid cloud, private cloud, public cloud, internet service, software as a service, database-as-a-service, data protection, State register of potentially dangerous objects.

\section{Introduction}

The great number of various state information resources (registers, cadastres, databases, etc.) is conducted in Ukraine, the majority from which are created on technology "client-server" and function in the separate closed information systems. For conducting such systems create special departments, which provide information entering, conducting, actualization and administration of databases, etc. Besides, many systems are created by a regional principle: in regions are conducted separate parts of systems and at the central office these parts are uniting in general database on the state.

The process of guiding of state information resource, in general view, is reduced to such circuit: legal or physical persons are designed information, on the paper data storage, for depositing in the register, state structure sre checking this data, possible correction, depositing in information system (in many cases this systems are - regional, with the subsequent date transmission in a central information system), designing and provision document about registration for legal or physical person, preparation and information provision behind requests, system administration, etc. Such system of guiding of state information resources is ineffective, low efficiency of such systems representations in Figure 1. 
In such, process of guiding of information resource are considerable expenses of human resources, an amount of employees which participate in information system guiding take place makes hundreds: in each of offices there are doubling subdividing of guiding and administration of system, subdividing which process the input information on paper carriers, etc., there are 27 territorial representations of authority with appropriate subdividing of guiding of system. Also in each territorial subdividing a significant amount of hardware support (the server, workstations) and the license software (operating systems, a DBMS, office programs, etc.) is used and the amount of units hardware and the software makes already thousand elements. In the course of guiding, as a rule, the state information system develops extensively, demanding for the development more and more human, financial, program and hardware resources. One of ways of the decision of this problem is technology usage cloud computing.

The purpose of this Article is the creation of a conceptual basis for implementation of the technology of cloud computing in the process of developing and maintaining the State register of potentially dangerous objects.

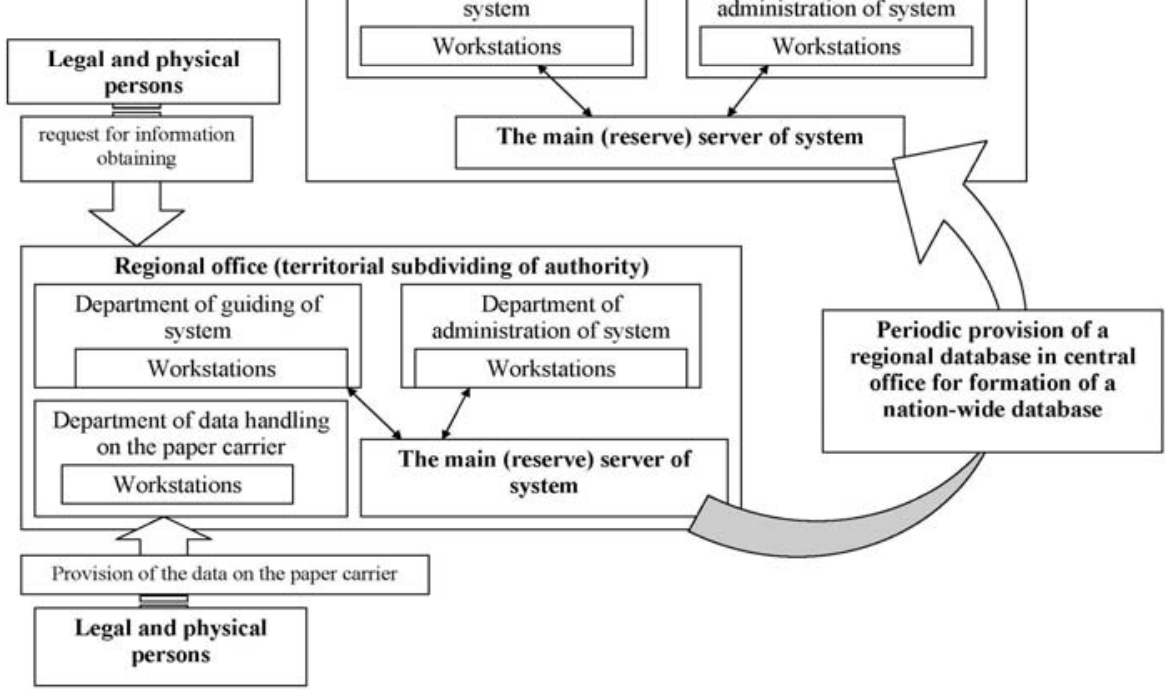

Figure 1: The generalized circuit of guiding of the state information system. 


\section{Technology of cloud computing in the creation of the state information system}

\section{Elements cloud computing}

Cloud computing - a large-scale distributed computing paradigm that is driven by economies of scale, in which a pool of abstracted, virtualized, dynamically-scalable, managed computing power, storage, platforms, and services are delivered on demand to external customers over the Internet. ${ }^{1}$

The main idea of usage cloud computing for creation of a corporate network (information system), including state, consists that the organizations should not create the own data-centres, to fulfils installation and attending of a considerable quantity of the software, to accompany the automated systems, etc. Fulfilling exact calculation of resources of own data-centres for systems which permanently develop are difficult, therefore these resources will be superfluous or insufficient that leads to excessive expenses. Development of information systems in authorities can demand magnification or reduction of resources, their reallocation including in regions. The technology cloud computing allows to solve all these questions.

Among basic elements cloud computing, ${ }^{2}$ which can be used for creation of a corporate network, including state, it is necessary to select the following options:

Software as a Service: SaaS delivers a packaged or equivalent commercial software application to end users over the Internet with a subscription or usage-based pricing model, as opposed to a traditional lifetime license for a particular. The software works on the server of the data-centre and gives to the user results. Thus the user pays only temporal usage of this software or if the software is own development or there are rights to its usage - free of charge.

Database as a Service, DaaS: - functioning and storage of databases in the form of services, this element it is possible to consider provision of resources as one of varieties SaaS.

Infrastructure as a Service: IaaS provides traditional data centre resources, such as highly scalable virtualized computing power, memory and storage, over a network (typically, but not necessarily, the Internet) and usually with a subscription or per usage pricing model. It allows not using at each office a great number of servers, the network equipment, the software and subdividing on attending of this equipment.

Platform as a Service, PaaS provides information resources and disk space in necessary volume in the form of service. 


\section{The circuit of the organization of a corporate network (information system) on a basis cloud computing}

The corporate network (information system) with usage cloud computing can look so: workstations in central and regional offices have access to resources uniform to the data-centre through Internet, with getting the access to necessary resources in the form of Internet-services (the software, the virtual computer network, access to databases, obtaining of resources for handling of great volumes of the information), the databases in the data-centre are stored and conducted, data-centre are producing the uniform loading of physical information resources with using the technology of virtual servers, integration of databases etc. (Figure 2). Companies Google and Amazon already render services cloud computing with the operating data-centres which provide creation of a necessary infrastructure and support key technologies of virtualization and sharing of resources.

However, it is necessary to design new administrative processes or to modify existing, for the purpose of their adaptation to SaaS. ${ }^{3}$ In that case, each administrative process should come to an end with accurately certain result that allows beginning performance of following process etc. That is process of guiding of the state information resource is necessary for dividing into stages, each of which can be presented in the form of Internet-services. Criteria of allocation to stages: presence of one type of users of service, logical completeness of action and presence of the formalized result.

\section{Organization of guiding State register PDOs on basis cloud computing}

\section{State register of $\mathrm{PDO}$}

The State register of potentially dangerous objects (State register PDO) is the automated system of the registration and information processing about potentially dangerous objects and it conducted by State department of insurance fund of the documentation (IFD). For today the State register PDO stores the full information about more 22 thousand objects. Process of guiding of State register PDO is regulated by is standard-legal basis and a general view looks so: designing by the subject of economic activities of passport PDO on the paper, transferring the passport PDO to State department IFD, its analysis, deposit the information of passport PDO in database of State register PDO, assignment the registration number for object, design and transfer the certificate on registration PDO in the register to the subject of economic activities, guiding by the subject of economic activities of passport PDO (design of changes in the passport or creation a new passport PDO), depositing of this data in a register database, database administration, preparation and information provision on requests, etc. 
However the further development of the register restrains the questions connected to necessity of essential magnification of human, financial, program and hardware resources which are attracted in its guiding. One of ways of the decision of this problem is technology implementation cloud computing in process of guiding of the register. But in this case it is necessary to mark that in the form of internet-services components of process of guiding of the register should appear. Thus the majority of components of process of guiding of the register will be implemented in the form of SaaS and, to be given to users as internet-services. Subjects of economic activities and experts authorities will be users.

\section{Organization of process of guiding of the register with usage internet-services}

Process of design and transfer of passport PDO. For the purpose of passage to paperless technology of design of passports PDO it is necessary to develop a program application which will give possibility of filling of columns of passport PDO, carrying out of check of passport PDO to requirements and usage of the electronic signcode signature. Such program application should be given to subjects of economic activities in a type internet-services SaaS. After depositing the data, passport PDO should be stored in a separate database (service DaaS) for check and depositing of the information in register.

Process of checking and depositing of passport PDO in the State register PDO. For reviewing saved at the previous stage in database of passports PDO it is necessary to develop a program application which will be accessible to experts of State department IFD in a type internet-services SaaS. After check of the data of passport PDO the program application should import the given passports to the database of the register and supervise slip number provision.

Process of designing of the Certificate about object registration in the State registers PDO (Certificate). After establishment for experts of State department IFD access to internet-services SaaS to a program application which allows making out Certificates in electronic form should be given object of slip number, and to the State department ISD manual allows putting sign-code signatures. After this, the Certificate should be transferred to a separate database, access to which representatives of State department IFD and the subject of economic activities which with a program application in a type internet-services SaaS should receive the Certificate with the electronic sign-code signature, and will have only access to service the subject can receive under condition of depositing of the registration data (the most simple usage of the electronic signcode signature which was used at the previous stage). 


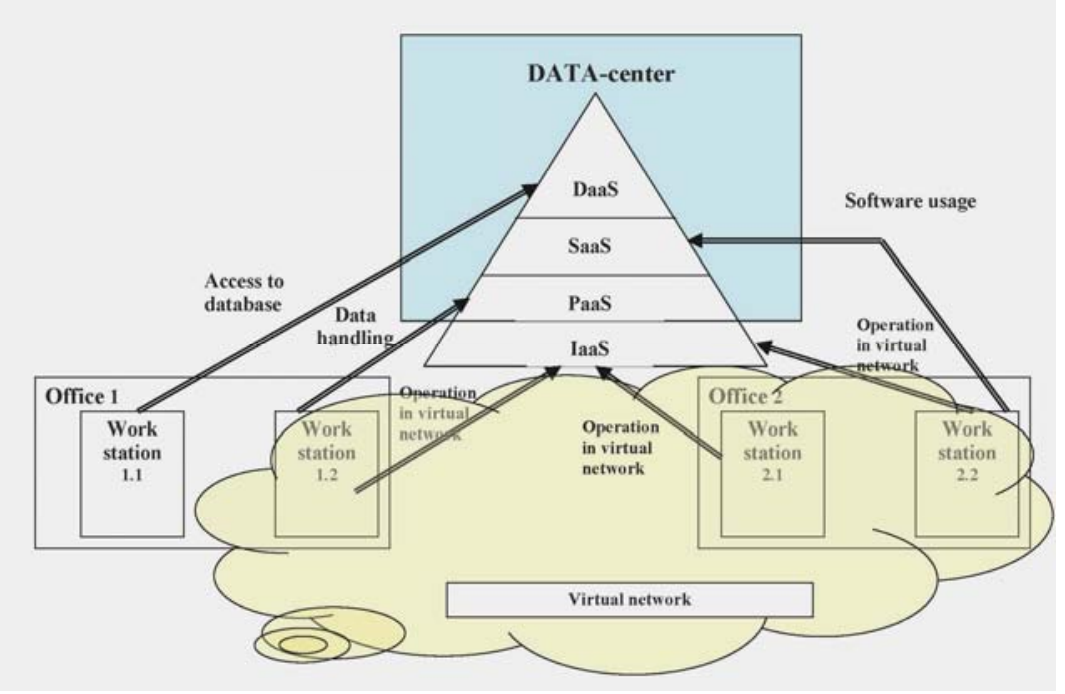

Figure 2: The circuit of the organization of a corporate network on a basis cloud computing.

Process of granting information from the State register PDO. The part of the software of the register which fulfills function on formation requests of the data should be accessible in a type internet-service SaaS, access to service should be given accurately certain list of users.

Database administration. The register database should be accessible to experts of State department IFD in a type internet-services DaaS, and processes of its administration fulfilled by data-center means.

Operation of experts of State department IFD with the register. In case of technology usage cloud computing the access for register resources is reached by provision internet-services types SaaS and PaaS. All structural subdividings which have a access for register are unite in virtual network.

The data-center should give and other services for support of functionized the organization (document circulation, search and information storage, etc.). The general circuit of the organization of guiding of State register PDO on cloud computing-basis is presented in Figure 3. 


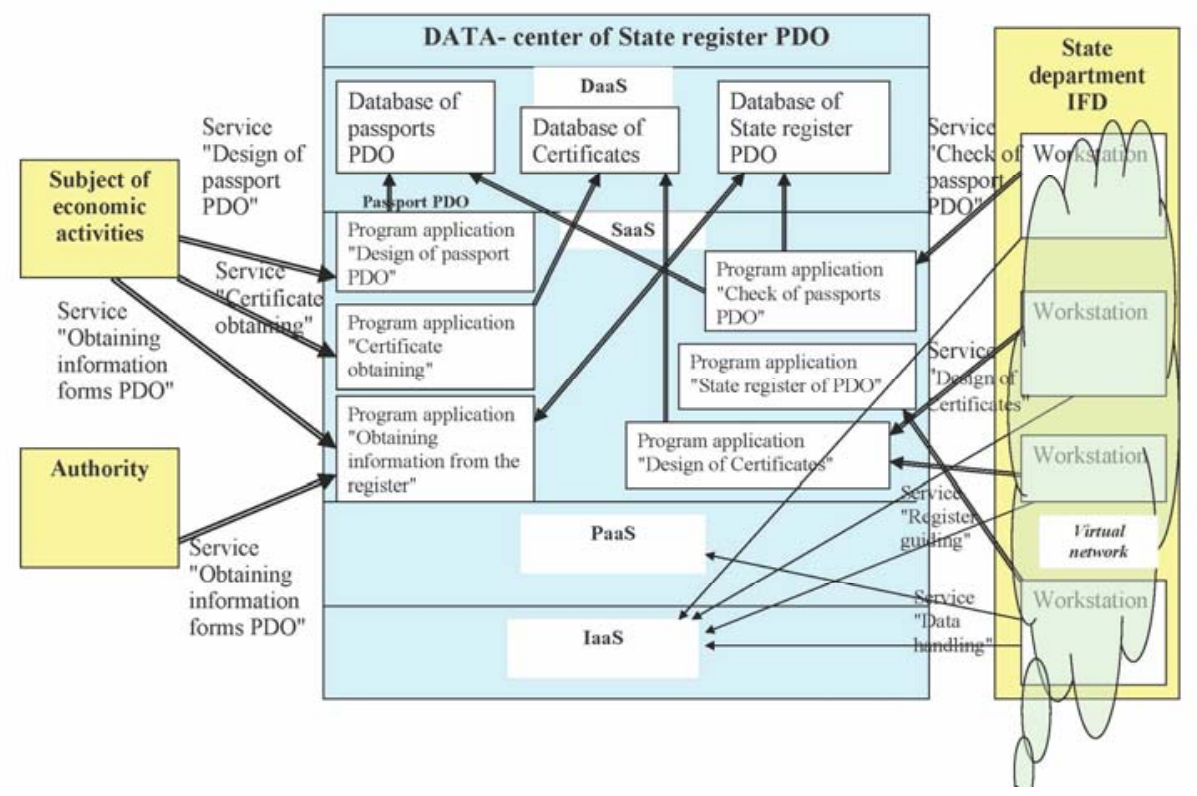

Figure 3: The circuit organization of guiding of State register PDO on cloud computing-basis.

\section{Questions of data protection in cloud computing}

The cloud computing technology, as well as any new technology, creates both new possibilities of layout and information processing and new risks concerning information protection. In certain cases relocation of the data in cloud gives possibility repeatedly to programmed out-of-date applications and an infrastructure for the purpose of performance of safety requirements, but in other cases there is a risk of reduction of security level. Basic elements which have influence on information security level are: a choice of cloud-models, a method of their development, physical layout of resources and attributes of control3. The main problem question of protection of the information is that in technology cloud computing the considerable part of powers on information protection is transferred to the provider and the proprietor of the data cannot essentially influence a security policy which is implemented by the provider. This question is actual for the state information resources, requirements on which protection in Ukraine are installed legislatively and regulated by a considerable quantity of standard documents. In this article considered the partial solution of a 
problem of safety of the state information resources in cloud regarding a choice of cloud-models, a method of their development and physical layout of resources.

\section{Physical layout of resources}

The majority of contracts which can be made between the provider and the proprietor of the information, operations on data storage lay to the provider who can allocate the data in the data-centres worldwide. That is, in that case one state washes practically to give another the important information for itself that explicitly contradicts requirements of national safety. In work4 for the decision this question offered to provide in contracts with the provider the possibility of determination of geographical layout of the data and presence of control facilities for country determination in which territory server's dataful are physically allocated. But such approach contradicts practice of protection of the information. State structures must be creation of the state data-centre which will guarantee physical layout of the information in territory of Ukraine is more comprehensible and to provide that part of protection of the information which is laid to the provider.

\section{Cloud-models}

Irrespective of model of service, which is used (SaaS, PaaS, or IaaS) exists four models of development for cloud which provide implementation of different requirements: ${ }^{4}$

Public Cloud. The cloud infrastructure is made available to the general public or a large industry group and is owned by an organization selling cloud services.

Private Cloud. The cloud infrastructure is operated solely for a single organization. It may be managed by the organization or a third party, and may exist on-premises or off- premises.

Community Cloud. The cloud infrastructure is shared by several organizations and supports a specific community that has shared concerns (e.g., mission, security requirements, policy, or compliance considerations). It may be managed by the organizations or a third party and may exist on-premises or off-premises.

Hybrid Cloud. The cloud infrastructure is a composition of two or more clouds (private, community, or public) that remain unique entities but are bound together by standardized or proprietary technology that enables data and application portability (e.g., cloud bursting for load-balancing between clouds).

For state information resources model Public Cloud is insufficient, as in this case there is a general access to an infrastructure, depending on assignment of the state information resources, models Private Cloud, Community Cloud that Hybrid Cloud are more suitable. Model Private Cloud can be used for resources which provide excep- 
tional functioning of authorities and deriving or information transfers in do not demand out of. Model Community Cloud can be used for resources which are jointly used by restricted number of authorities (the separate closed community) and also deriving or information transfers in do not demand out of. For the majority of databases which are conducted by authorities and receive the information immediately from subjects of the economic activities, model Hybrid Cloud which allows to unite two models will be the most suitable: Public Cloud - to which infrastructure subjects of economic activities on the basis of which data the state information resource and model Private Cloud in which the authority will produce immediate handling and information storage is formed. In each of models there will be databases, and interaction between Public Cloud and Private Cloud will be provided in a type internet-services SaaS exceptional from Private Cloud, in Public Cloud there will be services for access from Private Cloud.

\section{Usage of model Hybrid Cloud for guiding of State register PDO}

For usage of model Hybrid Cloud (Figure 4) it is necessary to divide information flows on two parts: which immediately concern subjects of economic activities and what are internal information flows of State department IFD during register guiding. Thus it is necessary to consider that the greatest importance is carried by the shown data of State register PDO access to which should be organic. Information flows have been defined in article "Organization of process of guiding of the register with usage internet-services."

Process of design and transfer of passport PDO. Information flows of this process concern immediately subjects of the economic activities, therefore appropriate service and a database of passports PDO should be allocated in infrastructure Public Cloud.

Process of checking and depositing of passport PDO in the State register PDO. This process refer to experts of the State department IFD, therefore the appropriate program application for check and depositing of passports in a register database should allocated in infrastructure Private Cloud and have access to a database of passports PDO which is allocated in Public Cloud. After check of the data of passport PDO its information is imported to a database of State register PDO which is the main object of protection and allocated in infrastructure Private Cloud.

Process of designing of the Certificate. Certificates are made out and affirm with State department IFD on the basis of the data of the State register PDO, therefore the appropriate program application is allocated in infrastructure Private Cloud. After designing, the electronic Certificate should be moved to an appropriate database from which the subject of economic activities should receive Certificate, after identification, this database and program application for obtaining of Certificates are allocated in Public Cloud. 


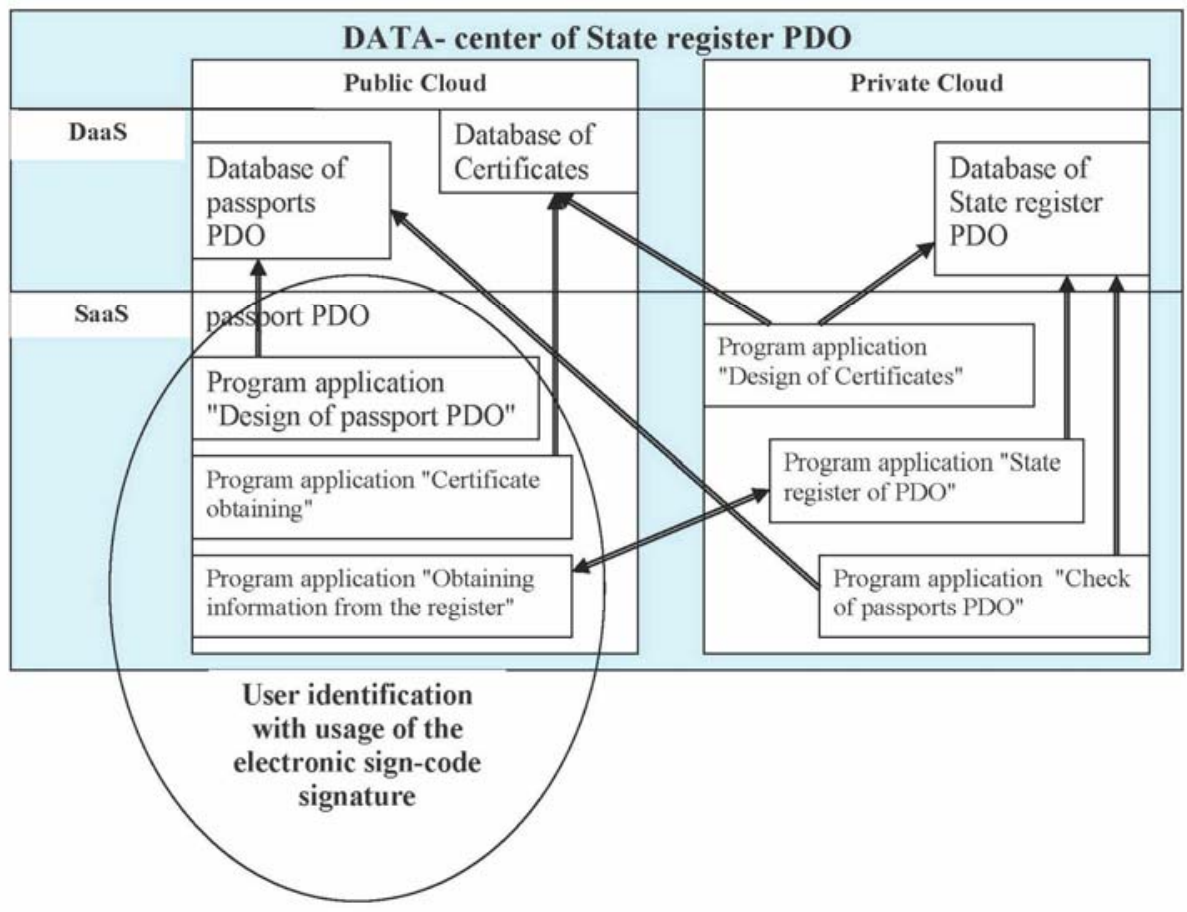

Figure 4: The circuit of model Hybrid Cloud of guiding of State register PDO at level SaaS.

Process of granting information from the State register PDO. This process is one of the most vulnerable from the point of view of information protection because in there is a necessity of access to a register database in Private Cloud a program application from Public Cloud.

One of methods of the decision of this problem - the program application should form request about obtaining of the information of the register, and request implementation to be fulfilled by experts of State department IFD means from Private Cloud then the received information is transferred to the customer in Public Cloud.

Weak spot in the similar circuit on model Hybrid Cloud is identification and access demarcation to the information of subjects of economic activities. One of solutions of this question - is offered usage of the electronic sign-code signature. Thus, depending on an amount of clients, interaction with the certificated center of keys or creation 
within the limits of Hybrid Cloud own center of keys. Thus, its sign-code signature becomes a user.

\section{Conclusion}

In article sentences on the organization of the state corporate networks, including the information resources of authorities oriented on guiding, on the basis of technology cloud computing are prepared. The technology offered to usage allows reducing expenses for creation and system service of information resources, doing it by more flexible, to simplify the order of provision of the information. It is developed the circuit of the organization of guiding of State register PDO on the basis of model Hybrid Cloud.

The further direction of development of processes of guiding of information resources of authorities on the basis of technology cloud computing is development of models of protection of the information in infrastructure Hybrid Cloud, determination of methods of integration of databases for support of implementation of technology of virtualization and sharing of resources in the data-centers. The development is demanded by the theoretical decision of problems of creation of information systems on the basis of technology cloud computing, creation of models and the decision of a question of optimization of information flows in them.

\section{Notes:}

1 Ian Foster, Yong Zhao, Ioan Raicu, and Shiyong Lu, "Cloud Computing and Grid Computing 360-Degree Compared," <www.people.cs.uchicago.edu/ iraicu/publications/ 2008_GCE08_Clouds_Grids.pdf> (13 Nov. 2008).

2 Roger Jennings, Cloud Computing with the Windows ${ }^{\circledR}$ Azure ${ }^{\mathrm{TM}}$ Platform (Indianapolis, IN: John Wiley, 2009).

${ }^{3}$ Hanu Kommalapati, "Windows Azure Platform for Enterprises," MSDN Magazine, $<$ http://msdn.microsoft.com/en-us/magazine/ee309870.aspx> (01 Feb. 2012).

${ }^{4}$ Cloud Security Alliance, Security Guidance for Critical Areas of Focus in Cloud Computing V2.1 (December 2009) <www.cloudsecurityalliance.org/guidance/csaguide.v2.1.pdf>; Eric A. Marks and Bob Lozano, Executive's Guide to Cloud Computing (Hoboken, NJ: John Wiley, 2010).

ANDREY MELENETS is head of IT-department of the State department of insurance fund of the documentation. He received the specialist degree in software of the automated systems from National Aerospace University (KhAI) in 1999, and the degree master of the government from National academy of the government at President of Ukraine in 2006. He present research interests include creating and integration the state corporate information systems. 